\title{
Pengaruh Penerapan K3 (Keselamatan dan Kesehatan Kerja) Pada Pembangunan Laboratorium Komputer SMP It Al-Haromain, SMPS Darul Ulum, Dan SMP Badrul Ulum
}

\author{
Dedy Asmaroni ${ }^{1}$ dan Ahmad Fatoni ${ }^{2}$ \\ ${ }^{1}$ Program Studi Teknik Sipil, Fakultas Teknik, Universitas Madura, Pamekasan \\ ${ }^{2}$ Program Studi Teknik Sipil, Fakultas Teknik, Universitas Madura, Pamekasan \\ E-mail: dedyasmaroni@gmail.com
}

\begin{abstract}
ABSTRAK: Dalam mewujudkan suatu pembangunan konstruksi yang baik, tentunya kita harus melihat keselamatan dan kesehatan kerja (K3). Karena secara umum proyek pembangunan direncanakan untuk mendirikan sebuah gedung yang berfungsi untuk kepentingan orang banyak, dimana pembangunan tersebut memiliki standart pembangunan gedung berbasis pemerintah dan semaksimal mungkin dalam pelaksanaan tersebut tidak mengalami resiko-resiko yang mempengaruhi dalam pekerjaan, khususnya pada keselamatan dan kesehatan kerja (K3) pada pembangunan konstruksi gedung. Pada Penelitian ini membahas mengenai pengaruh penerapan keselamatan dan kesehatan kerja (K3) terhadap kinerja pekerja proyek konstruksi pembangunan ruang laboratorium komputer SMP IT Al-Haromain, SMPS Darul Ulum dan SMP Badrul Ulum. Dari hasil Uji t : Ketiga variabel tidak berpengaruh terhadap variabel (Y), sedangkan dari hasil uji f didapat Kecelakaan Kerja memiliki pengaruh yang paling dominan terhadap Pengaruh K3 Terhadap Produktivitas Pekerja pada proyek Pembangunan Laboratorium Komputer di Kabupaten Pamekasan.
\end{abstract}

\section{PENDAHULUAN}

\section{1) Latar Belakang}

Pembangunan proyek konstruksi bangunan gedung di indonesia provinsi jawa timur khususnya di wilayah pamekasan madura. Setiap proyek konstruksi selalu di hadapkan pada kemungkinan terjadinya berbagai macam resiko. Semakin tinggi tingkat kompleksitas suatu proyek, maka semakin besar pula tingkat resiko yang akan di terima. Resiko ini akan memberikan pengaruh terhadap keselamatan dan kesehatan kerja (K3) dalam pelaksanaan proyek itu sendiri.

Dalam mewujudkan suatu pembangunan konstruksi yang baik, tentunya kita harus melihat keselamatan dan kesehatan kerja (K3). Karena secara umum proyek pembangunan direncanakan untuk mendirikan sebuah gedung yang berfungsi untuk kepentingan orang banyak, dimana pembangunan tersebut memiliki standart pembangunan gedung berbasis pemerintah dan semaksimal mungkin dalam pelaksanaan tersebut tidak mengalami resiko-resiko yang mempengaruhi dalam pekerjaan, khususnya pada keselamatan dan kesehatan kerja (K3) pada pembangunan konstruksi gedung.

Dalam pembangunan tentunya ada resiko keselamatan dan kesehatan kerja (K3), hal ini dapat di katakan suatu akibat yang mungkin terjadi secara tidak terduga pada suatu proyek. Walaupun suatu kegitan telah di rencanakan sebaik mungkin, namun tetap mengandung ke tidak pastian pada suatu proyek untuk tidak terkendala oleh keselamatan dan kesehatan kerja. Karena resiko pada suatu proyek tidak dapat di hilangkan akan tetapi bisa di kurangi atau di minimalisir.

Keselamatan dan kesehatan kerja (K3) merupakan salah satu faktor penting agar tercapai kualitas produk yang baik dan tercapainya keselamatan kerja dalam pelaksanaan suatu pekerjaan yang terjamin, sehingga kesejahteraan pekerja dapat lebih ditingkatkan. Sistem keselamatan dan kesehatan kerja (K3) yang baik dapat meminimalkan resiko terjadinya kecelakaan kerja yang menimpa fisik ataupun mental dari pekerja.

Perusahaan merupakan spesialisasi dalam ilmu kesehatan beserta prakteknya dengan mengadakan penilaian kepada faktor-faktor penyebab penyakit dalam lingkungan kerja dan perusahaan melalui pengukuran yang hasilnya dipergunakan untuk dasar tindakan korektif dan bila perlu pencegahan kepada lingkungan tersebut, agar pekerja dan masyarakat sekitar perusahaan terhindar dari bahaya akibat kerja, serta dimungkinkan untuk mengecap derajat kesehatan setinggi-tinginya (Anies, 2005).

Pelaksanaan keselamatan dan kesehatan kerja adalah suatu kondisi dalam pekerjaan yang sehat dan aman baik itu bagi pekerjaannya, perusahaan maupun bagi masyarakat dan lingkungan sekitar pabrik atau tempat kerja tersebut. Keselamatan dan kesehatan kerja juga merupakan suatu usaha untuk mencegah setiap perbuatan atau kondisi tidak selamat, yang dapat mengakibatkan kecelakaan.

Keselamatan dan kesehatan kerja (K3) sebagai salah satu aspek perlindungan tenaga kerja memiliki peran yang 
besar dalam upaya meningkatkan produktivitas perusahaan (Sedarmayanti, 2009).

Menyadari pentingnya keselamatan dan kesehatan kerja (K3) agar dapat memberi rasa aman dan mencegah kecelakaan kerja sehingga dapat meningkatkan semangat ataupun kinerja para pekerja lainnya. Penelitian membahas mengenai pengaruh penerapan keselamatan dan kesehatan kerja (K3) terhadap kinerja pekerja proyek konstruksi pembangunan ruang laboratorium komputer SMP IT Al-Haromain, SMPS Darul Ulum dan SMP Badrul Ulum.

\section{METODE PENELITIAN}

Langkah-langkah pada penelitian ini terdapat pada diagram alir Gambar 1.

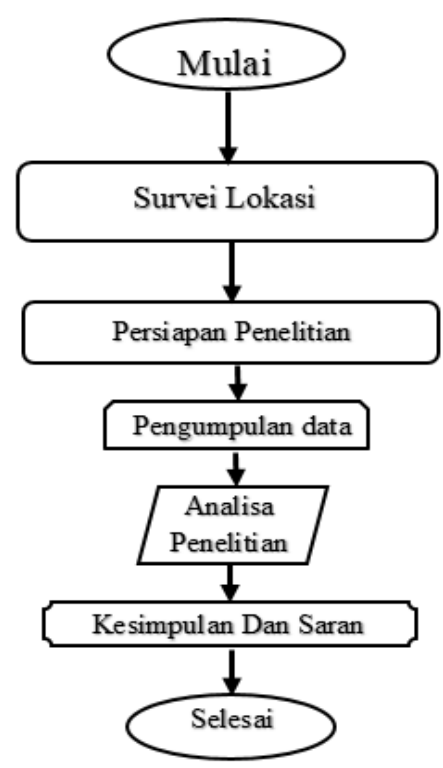

Gambar 1. Diagaram Alir Penelitian

\section{HASIL PENELITIAN DAN PEMBAHASAN}

\section{1) Pengumpulan Data}

Penelitian telah dilakukan terhadap 25 responden. Pengumpulan data dilakukan dengan membagikan kuesioner. Untuk membantu dan memperjelas jawaban dari pertanyaan dilakukan juga wawancara kepada beberapa pekerja yang telah mengisi kuisioner.

Pelaksanaan pengumpulan data penelitian dilakukan pada tiga proyek Pembangunan Laboratorium komputer di Kabupaten Pamekasan.

- SMPS Darul Ulum, Kec. Waru, Sana Laok, Kabupaten Pamekasan sebanyak 10 responden.

- SMPI Badrul Ulum, Kec. Waru, Du'uman, Kabupaten Pamekasan sebanyak 10 responden
SMP It Al-haromain Kec. Pasean, Batu Kerbuy, Kabupaten Pamekasan sebanyak 5 responden.

\section{2) Uji Validitas}

Hipotesis : $\mathrm{H}_{0} \quad$ : Data yang diperoleh telah valid

$\mathrm{H}_{1} \quad$ : Data yang diperoleh tidak valid

Pengambilan Keputusan :

Jika pearson correlate $\geq \mathrm{r}$ tabel maka terima $\mathrm{H}_{0}$

Jika pearson correlate $<\mathrm{r}$ tabel maka terima $\mathrm{H}_{1}$

Berikut ini merupakan hasil menghitung $\mathrm{r}$ :

\section{- Data Informasi Statistik Keselamatn Kerja} (X1)

Tabel 1 Data Informasi Statistik Keselamatan Kerja (X1)

\begin{tabular}{|c|c|c|c|c|c|}
\hline \multirow{2}{*}{ Variabel } & Indikator & $\begin{array}{c}\text { Koefisien } \\
\text { Korelasi }\end{array}$ & $\begin{array}{c}\text { Nilai r } \\
\text { Tabel }\end{array}$ & $p$-value & Hasil \\
\hline \multirow{2}{*}{$\begin{array}{c}\text { Keselamatan } \\
\text { Kerja } \\
\text { (X1) }\end{array}$} & X1.A1 & 0,681 & 0,396 & 0,000 & Valid \\
\cline { 2 - 6 } & X1.A2 & 0,548 & 0,396 & 0,000 & Valid \\
\cline { 2 - 6 } & X1.A3 & 0,745 & 0,396 & 0,000 & Valid \\
\hline
\end{tabular}

Tabel 1 merupakan hasil pengujian validitas Keselamatan Kerja (X1) menggunakan software SPSS. Dari data Keselamatan Kerja (X1), pertanyaan X1.A1, $\mathrm{X} 1 . \mathrm{A} 2$ dan X1.A3 diperoleh nilai koefisien korelasi lebih besar dari $r$ tabel yaitu 0,396 sehingga dapat diputuskan bahwa data terima hipotesa nol dan kesimpulannya yaitu data yang diperoleh telah valid.

\section{- Data Informasi Statistik Kesehatan Kerja (X2)}

Tabel 2 Data Informasi Statistik Kesehatan Kerja (X2)

\begin{tabular}{|c|c|c|c|c|c|}
\hline Variabel & Indikator & $\begin{array}{c}\text { Koefisien } \\
\text { Korelasi }\end{array}$ & $\begin{array}{c}\text { Nilai r } \\
\text { Tabel }\end{array}$ & $p$-value & Hasil \\
\hline $\begin{array}{c}\text { Kesehatan } \\
\text { Keja } \\
(\mathrm{X} 2)\end{array}$ & $\mathrm{X} 2 . \mathrm{B} 1$ & 0,722 & 0,396 & 0,000 & Valid \\
\cline { 2 - 6 } & $\mathrm{X} 2 . \mathrm{B} 2$ & 0,765 & 0,396 & 0,000 & Valid \\
\hline
\end{tabular}

Tabel 2 merupakan hasil pengujian validitas Kesehatan Kerja (X2) menggunakan software SPSS. Dari data Kesehatan Kerja (X2), pertanyaan X2.B1 dan X2.B2 diperoleh nilai koefisien korelasi lebih besar dari $\mathrm{r}$ tabel yaitu 0,396 sehingga dapat diputuskan bahwa data terima 
hipotesa nol dan kesimpulannya yaitu data yang diperoleh telah valid.

\section{- Data Informasi Statistik Kecelakaan Kerja (X3)}

Tabel 3 Data Informasi Statistik Kecelakaan Kerja (X3)

\begin{tabular}{|c|c|c|c|c|c|}
\hline Variabel & Indikator & $\begin{array}{c}\text { Koefisien } \\
\text { Korelasi }\end{array}$ & $\begin{array}{c}\text { Nilai r } \\
\text { Tabel }\end{array}$ & $p$-value & Hasil \\
\hline \multirow{2}{*}{$\begin{array}{c}\text { Kecelakaan } \\
\text { Kerja } \\
\text { (X3) }\end{array}$} & X3.C1 & 0,812 & 0,396 & 0,000 & Valid \\
\cline { 2 - 6 } & X3.C2 & 0,926 & 0,396 & 0,000 & Valid \\
\hline
\end{tabular}

Tabel 3 merupakan hasil pengujian validitas Upah Bulanan (X3) menggunakan software SPSS. Dari data Metode Pelaksanaan (X3), pertanyaan X3.C1 dan X3.C2 diperoleh nilai koefisien korelasi lebih besar dari $r$ tabel yaitu 0,396 sehingga dapat diputuskan bahwa data terima hipotesa nol dan kesimpulannya yaitu data yang diperoleh telah valid.

\section{- Data Informasi Statistik PK3TPP (Y)}

Tabel 4 Data Informasi Statistik PK3TPP (Y)

\begin{tabular}{|c|c|c|c|c|c|}
\hline Variabel & Indikator & $\begin{array}{c}\text { Koefisien } \\
\text { Korelasi }\end{array}$ & $\begin{array}{c}\text { Nilai r } \\
\text { Tabel }\end{array}$ & $p$-value & Hasil \\
\hline $\begin{array}{c}\text { PK3TPP } \\
\text { (X4) }\end{array}$ & Y.D1 & 1,000 & 0,396 & 0,000 & Valid \\
\hline
\end{tabular}

Tabel 4 merupakan hasil pengujian validitas Pengaruh Keselamatan, Kesehatan dan Kecelakaan Kerja Terhadap Produktivitas Pekerja (Y) menggunakan software SPSS. Dari data PK3TPP (X4), pertanyaan Y1.D1. diperoleh nilai koefisien korelasi lebih besar dari $r$ tabel yaitu 0,396 sehingga dapat diputuskan bahwa data terima hipotesa nol dan kesimpulannya yaitu data yang diperoleh telah valid.

\section{3) Uji Reliabilitas}

Tabel 5 Hasil Uji Reliabilitas

\begin{tabular}{|l|l|c|c|l|}
\hline \multirow{2}{*}{ Variabel } & Indikator & $\begin{array}{c}\text { N on } \\
\text { Items }\end{array}$ & $\begin{array}{c}\text { Cronbach's } \\
\text { Alpha }\end{array}$ & Keterangan \\
\hline \multirow{2}{*}{$\mathrm{X}$} & Keselamatan kerja & 4 & 0,746 & Reliabel \\
\cline { 2 - 5 } & Kesehatan Kerja & 3 & 0,786 & Reliabel \\
\cline { 2 - 5 } & Kecelakaan Kerja & 3 & 0,903 & Reliabel \\
\hline Y & PK3TPP & 2 & 1,000 & Reliabel \\
\hline
\end{tabular}

Dari keterangan pada Tabel 4.5 di atas dapat diketahui bahwa masing-masing variabel memiliki Cronbach Alpha $>0,60$. Dengan demikian variabel X dan variabel Y dapat dikatakan reliabel.

\section{4) Asumsi Klasik}

\section{- Uji Normalitas}

Tabel 6 Uji Normalitas

\begin{tabular}{|l|c|}
\hline \multicolumn{1}{|c|}{$\begin{array}{c}\text { Uji kolmogorov- } \\
\text { smirnov }\end{array}$} & Unstandarize Residual \\
\hline $\begin{array}{l}\text { Nilai kolmogorov- } \\
\text { smirnov }\end{array}$ & 0,890 \\
\hline Sig & $0,200^{\mathrm{c}, \mathrm{d}}$ \\
\hline
\end{tabular}

Berdasarkan pada Tabel 6, uji Kolomorov Smirnov menunjukkan bahwa residual data yang didapat tersebut mengikuti distribusi normal, berdasarkan hasil output menunjukkan nilai Kolmogorov-Smirnov signifikan pada 0,200 >0,05. Dengan demikian, residual data berdistribusi normal dan model regresi telah memenuhi asumsi normalitas.

\section{- Uji Multikolinearitas}

Tabel 7 Uji Multikolinearitas

\begin{tabular}{|l|l|l|}
\hline \multirow{2}{*}{ Mode1 } & \multicolumn{2}{|c|}{$\begin{array}{l}\text { Collinearity } \\
\text { Statistic }\end{array}$} \\
\cline { 2 - 3 } & Tolerance & VIF \\
\hline (Constant) & & \\
\hline X1 (Keselamatan Kerja) & 0,643 & 1,555 \\
\hline X2 (Kesehatan Kerja) & 0,949 & 1,054 \\
\hline X3 (Kecelakaan Kerja) & 0,651 & 1,536 \\
\hline
\end{tabular}

Dari hasil pengujian multikolinearitas yang ada pada Tabel 7 diketahui bahwa nilai variance inflation factor (VIF) ke tiga variabel, yaitu lebih kecil dari 10 dan nilai tolerance lebih besar dari 0,10, sehingga dapat disimpulkan bahwa tidak ada multikolinearitas antar variabel independent dalam model regresi. 


\section{- Uji Heteroskedastisitas}

Tabel 8 Uji Heteroskedastisitas

\begin{tabular}{|l|l|l|}
\hline Variabel & Sig & Kriteria \\
\hline $\mathrm{X}_{1}$ & 0,148 & Tidak terjadi heteroskedastisitas \\
\hline $\mathrm{X}_{2}$ & 0,737 & Tidak terjadi heteroskedastisitas \\
\hline $\mathrm{X}_{3}$ & 0,106 & Tidak terjadi heteroskedastisitas \\
\hline
\end{tabular}

Berdasarkan Tabel 8 uji heteroskedastisitas dengan metode glejser tidak ada variabel yang terjadi heteroskedastisitas karena diperoleh nilai signifikansi lebih besar 0,05 , sehingga dapat disimpulkan data tidak terjadi masalah heteroskedastisitas.

\section{- Uji Autokorelasi}

Tabel 9 Uji Autokorelasi

\begin{tabular}{|c|c|c|c|c|c|}
\hline Model & R & R Square & $\begin{array}{c}\text { Adjusted R } \\
\text { Square }\end{array}$ & $\begin{array}{c}\text { Std. Error of the } \\
\text { Estimate }\end{array}$ & $\begin{array}{c}\text { Durbin- } \\
\text { Watson }\end{array}$ \\
\hline 1 & 0,357 & 0,128 & 0,003 & 0,76254 & 2,387 \\
\hline
\end{tabular}

Berdasarkan nilai uji statistik Durbin-Watson pada Tabel 9 dalam penelitian ini yaitu 2,387, selanjutnya dibandingkan dengan nilai tabel signifikan 5\% $(0,05)$ dengan jumlah sampel 25 dan jumlah variabel independent $3(\mathrm{~K}=3)=5,24$ sehingga didapatkan hasil $\mathrm{dU}$ dari tabel $\mathrm{r}=$ 1,902. Nilai dL 1,228 lebih kecil dari batas dU 1,6540 kurang dari (4$\mathrm{dU})=4-1,6540=2,346$. Sehingga dapat disumpulkan bahwa tidak terjadi autocorrelation.

\section{5) Analisa Deskriptif}

\section{- Keselamatan Kerja (X1)}

Tabel 10 Uji Analisa Deskriptif Keselamatan Kerja

\begin{tabular}{|l|r|r|r|r|r|r|}
\hline \multirow{2}{*}{ Pernyataan } & \multicolumn{5}{|c|}{ Variabel Keselamatan Kerja (X1) } \\
\cline { 2 - 7 } & \multicolumn{2}{|c|}{ X1.A1 } & \multicolumn{2}{|c|}{ X1.A2 } & \multicolumn{2}{|c|}{ X1.A3 } \\
\cline { 2 - 7 } & $\begin{array}{r}\text { Freque } \\
\text { ncy }\end{array}$ & $\begin{array}{r}\text { Perc } \\
\text { ent } \\
(\%)\end{array}$ & $\begin{array}{c}\text { Freque } \\
\text { ncy }\end{array}$ & $\begin{array}{r}\text { Perc } \\
\text { ent } \\
(\%)\end{array}$ & $\begin{array}{r}\text { Freque } \\
\text { ncy }\end{array}$ & $\begin{array}{r}\text { Perc } \\
\text { ent } \\
(\%)\end{array}$ \\
\hline $\begin{array}{l}\text { Sangat Tidak } \\
\text { Setuju }\end{array}$ & 1 & 4,0 & - & - & - & - \\
\hline Tidak Setuju & 2 & 8,0 & 7 & 28,0 & 4 & 16,0 \\
\hline Ragu-Ragu & 6 & 24,0 & 11 & 44,0 & 5 & 20,0 \\
\hline Setuju & 14 & 56,0 & 7 & 28,0 & 14 & 56,0 \\
\hline $\begin{array}{l}\text { Sangat } \\
\text { Setuju }\end{array}$ & 2 & 8,0 & - & - & 2 & 8,0 \\
\hline Total & 25 & 100, & 25 & 100, & & 100, \\
\hline
\end{tabular}

Berdasarkan Tabel 10 maka didapat untuk pernyataan pertama X1.A1 sebanyak 14 responden lebih berpendapat setuju dengan persentase 56\%. Untuk pernyataan kedua X1.A2 sebanyak 11 responden yang menjawab ragu-ragu dengan persentase $44 \%$ dan Untuk pernyataan ketiga X1.A3 sebanyak 14 responden yang menjawab setuju dengan persentase $56 \%$.

\section{- Kesehatan Kerja (X2)}

Berdasarkan Tabel 12 maka didapat untuk pernyataan pertama X2.B1 sebanyak 15 responden lebih berpendapat setuju dengan persentase $60 \%$. Untuk pernyataan kedua X2.B2 sebanyak 11 responden yang menjawab setuju dengan persentase $44 \%$.

Tabel 11 Uji Analisa Deskriptif Kesehatan Kerja

\begin{tabular}{|l|r|r|r|r|}
\hline \multirow{2}{*}{\multicolumn{1}{|c|}{ Pernyataan }} & \multicolumn{4}{|c|}{ Variabel Kesehatan Kerja (X2) } \\
\cline { 2 - 5 } & \multicolumn{2}{|c|}{ X2.B2 } & \multicolumn{2}{c|}{ X2.B2 } \\
\cline { 2 - 5 } & Frequency & $\begin{array}{c}\text { Percent } \\
(\%)\end{array}$ & Frequency & $\begin{array}{c}\text { Percent } \\
\text { (\%) }\end{array}$ \\
\hline Sangat Tidak Setuju & 1 & 4,0 & 1 & 4,0 \\
\hline Tidak Setuju & 9 & 36,0 & 7 & 28,0 \\
\hline Ragu-Ragu & 5 & 20,0 & 6 & 24,0 \\
\hline Setuju & 9 & 36,0 & 8 & 32,0 \\
\hline Sangat Setuju & 1 & 4,0 & 3 & 12,0 \\
\hline Total & 25 & 100,0 & 25 & 100,0 \\
\hline
\end{tabular}

Berdasarkan Tabel 11 maka didapat untuk pernyataan pertama X2.B1 sebanyak 9 responden lebih berpendapat setuju dan 9 responden tidak setuju dengan persentase $56 \%$. Untuk pernyataan kedua X2.B2 sebanyak 8 responden yang menjawab setuju dengan persentase $44 \%$.

\section{- Kecelakaan Kerja (X3)}

Tabel 12 Uji Analisa Deskriptif Kecelakaan Kerja

\begin{tabular}{|l|r|r|r|r|}
\hline \multirow{2}{*}{ Pernyataan } & \multicolumn{4}{|c|}{ Variabel Kecelakaan Kerja (X3) } \\
\cline { 2 - 5 } & \multicolumn{2}{|c|}{ X3.C1 } & \multicolumn{2}{c|}{ X3.C2 } \\
\cline { 2 - 5 } & Frequency & $\begin{array}{c}\text { Percent } \\
(\%)\end{array}$ & Frequency & $\begin{array}{c}\text { Percent } \\
(\%)\end{array}$ \\
\hline $\begin{array}{l}\text { Sangat Tidak } \\
\text { Setuju }\end{array}$ & - & - & 1 & 4,0 \\
\hline Tidak Setuju & 1 & - & 2 & 8,0 \\
\hline Ragu-Ragu & 15 & 60,0 & 11 & 44,0 \\
\hline Setuju & 9 & 36,0 & 1 & 4,0 \\
\hline Sangat Setuju & 25 & 100,0 & 25 & 100,0 \\
\hline Total & & - & 10 & 40,0 \\
\hline
\end{tabular}




\section{- Pengaruh K3 Terhadap Produktivitas Pekerja (Y)}

Berdasarkan Tabel 13 maka didapat untuk pernyataan Y1.D1 sebanyak 13 responden dengan persentase 52\% menjawab setuju.

Tabel 13 Uji Analisa Deskriptif Pengaruh K3 Terhadap Produktivitas Pekerja (Y)

\begin{tabular}{|l|r|r|}
\hline \multirow{2}{*}{\multicolumn{1}{|c|}{ Pernyataan }} & \multicolumn{2}{|c|}{ PK3TPP (Y) } \\
\cline { 2 - 3 } & \multicolumn{2}{|c|}{ Y1.D1 } \\
\cline { 2 - 3 } & Frequency & $\begin{array}{c}\text { Percent } \\
\text { (\%) }\end{array}$ \\
\hline Sangat Tidak Setuju & - & - \\
\hline Tidak Setuju & 1 & 4,0 \\
\hline Ragu-ragu & 7 & 28,0 \\
\hline Setuju & 13 & 52,0 \\
\hline Sangat Setuju & 4 & 16,0 \\
\hline Total & 25 & 100,0 \\
\hline
\end{tabular}

\section{6) Uji Regresi Linier Berganda}

Dari hasil perhitungan analisis regresi linier ganda pada Tabel 14 diperoleh koefisien masing-masing variabel dan dapat disusun persamaan linier berganda sebagai berikut :

$$
\mathrm{Y}=\mathrm{b} 0+\mathrm{b} 1 \cdot \mathrm{X}_{1}+\mathrm{b} 2 \cdot \mathrm{X}_{2}+\mathrm{b} 3 \cdot \mathrm{X}_{3}
$$

Maka persamaan tersebut menjadi :

$$
\begin{aligned}
& Y=2,066+-0,083 X_{1}+-0,197 X_{2}+- \\
& 0,366 X_{3}
\end{aligned}
$$

\begin{tabular}{|c|c|c|c|c|c|c|}
\hline & \multirow[t]{2}{*}{ Model } & \multicolumn{2}{|c|}{$\begin{array}{c}\text { Unstandardized } \\
\text { Coefficients }\end{array}$} & $\begin{array}{c}\text { Standardiz } \\
\text { ed } \\
\text { Coefficient } \\
\text { \& }\end{array}$ & \multirow[t]{2}{*}{$\mathrm{T}$} & \multirow[t]{2}{*}{ Sig. } \\
\hline & & B & $\begin{array}{l}\text { Std. } \\
\text { Error }\end{array}$ & Beta & & \\
\hline \multirow[t]{4}{*}{1} & (Constant) & 2,066 & 1,256 & & 1,645 & 0,115 \\
\hline & X1 (Keselamatan Kerja) & $-0,083$ & 0,344 & $-0,061$ & $-0,242$ & 0,812 \\
\hline & X2 (Kesehatan Kerja) & $-0,197$ & 0,199 & $-0,207$ & 0,990 & 0,334 \\
\hline & X3 (Kecelakaan Kerja) & $\begin{array}{c}- \\
0,366\end{array}$ & 0,309 & $-0,299$ & 1,184 & 0,250 \\
\hline
\end{tabular}

Tabel 14 Uji Regresi Linier Berganda

\section{- Uji Parsial atau Uji t}

Uji parsial atau uji t dilakukan dengan meliputi variabel terikat dan variabel bebas. Untuk variabel bebas terdiri dari Keselamatan Kerja, Kesehatan Kerja dan
Kecelakaan Kerja sedangkan untuk variabel terikat yaitu PK3TPP. Untuk hasil uji sendiri terdapat pada Tabel 15

\begin{tabular}{|c|c|c|c|}
\hline \multicolumn{2}{|r|}{ Model } & $\mathrm{T}$ & Sig. \\
\hline \multirow[t]{4}{*}{1} & (Constant) & 1,645 & 0,115 \\
\hline & $\begin{array}{l}\text { X1 (Keselamatan } \\
\text { Kerja) }\end{array}$ & $-0,242$ & 0,812 \\
\hline & $\begin{array}{ll}\text { X2 } & \text { (Kesehatan } \\
\text { Kerja) } & \end{array}$ & 0,990 & 0,334 \\
\hline & $\begin{array}{l}\text { X3 (Kecelakaan } \\
\text { Kerja) }\end{array}$ & 1,184 & 0,250 \\
\hline
\end{tabular}
berikut

Tabel 15 Nilai $t_{\text {Hiung }}$

Berdasarkan hasil dari Tabel 15 didapat nilai $t_{\text {hitung }}$ untuk variabel $X 1$ yaitu $-0,242$, sedangkan $t_{\text {tabel }}$ dengan menggunakan $\alpha / \mathrm{k}=0,05 / 5=0,01$ diketahui df $: \mathrm{n}$ $-\mathrm{k}-1=25-3-1=21$ adalah sebesar 2,518. Berdasarkan hasil tersebut maka $t_{\text {hitung }}(-0,242)<\mathrm{t}_{\text {tabel }}$ $(2,518)$. Berdasar pada hasil tersebut dapat diambil kesimpulan bahwa hipotesa 0 tidak dapat diterima, sehingga hipotesis "tidak pengaruh variabel Keselamatan Kerja (X1) terhadap variabel PK3TPP (Y1) " dapat diterima. Hal tersebut berarti bahwa variabel Keselamatan Kerja (X1) tidak berpengaruh terhadap variabel terikat yaitu PK3TPP (Y1).

\section{Analisa Uji Parsial atau Uji t Variabel X2}

Berdasarkan hasil dari Tabel 4.15 didapat nilai $t_{\text {hitung }}$ untuk variabel $\mathrm{X} 2$ yaitu 0,990 , sedangkan $t_{\text {tabel }}$ dengan menggunakan $\alpha / \mathrm{k}=0,05 / 5=0,01$ diketahui $\mathrm{df}: \mathrm{n}$ $-\mathrm{k}-1=25-3-1=21$ adalah sebesar 2,518. Berdasarkan hasil tersebut maka $t_{\text {hitung }}(0,990)<t_{\text {tabel }}$ $(2,518)$. Berdasar pada hasil tersebut dapat diambil kesimpulan bahwa hipotesa 0 dapat diterima, sehingga hipotesis "tidak ada pengaruh variabel Kesehatan Kerja (X2) terhadap variabel PK3TPP (Y1)" dapat diterima. Hal tersebut berarti bahwa variabel Kesehatan Kerja (X2) tidak berpengaruh terhadap variabel terikat yaitu PK3TPP (Y1).

\section{Analisa Uji Parsial atau Uji t Variabel X3}

Berdasarkan hasil dari Tabel 15 didapat nilai $t_{\text {hitung }}$ untuk variabel X3 yaitu 1,184, sedangkan $t_{\text {tabel }}$ dengan menggunakan $\alpha / \mathrm{k}=0,05 / 5=0,01$ diketahui df $: \mathrm{n}$ $-\mathrm{k}-1=25-3-1=21$ adalah sebesar 2,518. Berdasarkan hasil tersebut maka $t_{\text {hitung }}(1,184)<t_{\text {tabel }}$ (2,518). Berdasar pada hasil tersebut dapat diambil kesimpulan bahwa hipotesa 0 dapat diterima, sehingga hipotesis "tidak ada pengaruh variabel Kecelakaan Kerja (X3) terhadap variabel PK3TPP (Y1)" dapat diterima. Hal tersebut berarti bahwa variabel Kecelakaan Kerja (X3) tidak berpengaruh terhadap variabel terikat yaitu kualitas pekerjaan. 


\section{7) Uji Koefisien Determinasi Berganda}

Uji ini digunakan untuk menentukan persentase total variasi dalam variabel terikat yang diterangkan oleh variabel bebas, secara bersama-sama. Berikut hasil uji pada Tabel 16 menggunakan software SPSS :

Tabel 16 Model Summary

\begin{tabular}{|l|c|r|r|r|}
\hline Model & $\mathrm{R}$ & $\begin{array}{c}\mathrm{R} \\
\text { Square }\end{array}$ & $\begin{array}{c}\text { Adjusted } \\
\mathrm{R} \\
\text { Square }\end{array}$ & $\begin{array}{c}\text { Std. Error of } \\
\text { the Estimate }\end{array}$ \\
\hline 1 & $0,357^{\mathrm{a}}$ & 0,128 & 0,003 & 0,76254 \\
\hline
\end{tabular}

Dari Tabel 4.16 dapat diketahui hasil nilai koefisien determinasi berganda $\left(\mathrm{R}^{2}\right)$ dari analisis regresi linier berganda untuk masing-masing variabel baik secara parsial maupun simultan. Nilai $R$ Square $=0,357$ yang artinya pengaruh dari ketiga variabel sebesar 35,7\% selebihnya dipengaruhi oleh variabel lain.

Berdasarkan pembahasan dari tiga variabel tersebut dapat diambil kesimpulan bahwa variabel bebas berpengaruh terhadap variabel terikat dengan persentase $35,7 \%$ selebihnya $34,3 \%$ dipengaruhi oleh penelitian lain atau variabel lain. Sedangkan faktor yang dominan dari ketiga variabel yaitu variabel Kecelakaan Kerja (X3) dari pada variabel lainnya.

Dari hasil uji, dengan membandingkan nilai koefsien beta masing- masing variabel dapat diketahui variabel Kecelakaan Kerja memiliki nilai koefisien beta terbesar yaitu -0,299. Dengan nilai koefisien beta terbesar yaitu $-0,299$ dapat disimpulkan bahwa variabel Kecelakaan Kerja memiliki pengaruh yang paling dominan terhadap Pengaruh K3 Terhadap Produktivitas Pekerja pada proyek Pembangunan Laboratorium Komputer di Kabupaten Pamekasan.

\section{KESIMPULAN DAN SARAN}

- KESIMPULAN

Berdasarkan hasil dan pembahasan pada bab sebelumnya didapatkan kesimpulan sebagai berikut.

$\checkmark$ Dari hasil Uji t : Ketiga variabel tidak berpengaruh terhadap variabel (Y) yaitu Pengaruh Penerapan K3 terhadap Produktivitas Pekerja di Kabupaten Pamekasan khususnya pada Pembangunan Laboratorium Komputer di SMP It Al-Haromain, SMPS Darul Ulum, SMP Badrul Ulum.

$\checkmark$ Uji f : dengan membandingkan nilai koefsien beta masing- masing variabel dapat diketahui variabel Kecelakaan Kerja memiliki nilai koefisien beta terbesar yaitu -0,299. Dengan nilai koefisien beta terbesar yaitu $-0,299$ dapat disimpulkan bahwa variabel Kecelakaan Kerja memiliki pengaruh yang paling dominan terhadap Pengaruh K3 Terhadap Produktivitas Pekerja pada proyek Pembangunan Laboratorium Komputer di Kabupaten Pamekasan.

Uji Koefisen Determinasi Beganda dapat diketahui determinasi berganda $\left(\mathrm{R}^{2}\right)$ dari analisis regresi linier berganda untuk masing-masing variabel baik secara parsial maupun simultan. Nilai $\mathrm{R}$ Square $=0,357$ yang artinya pengaruh dari ketiga variabel sebesar $35,7 \%$ selebihnya dipengaruhi oleh variabel lain.

\section{- SARAN}

$\checkmark$ Dalam penelitian ini hanya menggunakan 3 variabel yaitu Keselamatan Kerja, Kesehatan Kerja dan Kecelakaan Kerja Untuk penelitian selanjutnya, perlu menambahkan variabel lain yang tidak masuk dalam penelitian ini, dan mungkin dapat memperoleh hasil yang lebih efisien.

$\checkmark$ Disarankan untuk tiap pekerjaan terutama bagi para kontraktor atau perencana menjaga keselamatan dan kesehatan agar tidak terjadi kecelakaan yang tidak di inginkan akbibat ke tidak pahaman tentang K3.

$\checkmark$ Disarankan penelitian ini dapat di lanjutkan untuk tiap pembangunan-pembanguna proyek khususnya di Kabupaten Pamekasan.

\section{DAFTAR PUSTAKA}

A.A. Anwar Prabu Mangkunegara. 2002.Manajemen Sumber Daya Manusia.Perusahaan. Bandung: PT. Remaja Rosdakarya.

Anies. Penyakit Akibat Kerja. Jakarta: PT Elex Media Komputindo; 2005.

Arikunto, S. 2006. Prosedur Penelitian Suatu Pendekatan Praktik Edisi Revisi VI. Jakarta : Rineka Cipta

AzmiD, Rahimah. 2009. Penerapan Sistem Manajemen Keselamatan dan Kesehatan Kerja oleh P2K3 Untuk Meminimalkan Kecelakaan Kerja di PT. 
Wijaya Karya Beton Medan Tahun 2008. (di

akses pada bulan Desember 2012)

(http://repository.usu.ac.id).

Candra, Lian. (2016).Analisis Potensi Kecelakaan Akibat Kerja Dengan Prosedur Hazard Identification, Risk Assesment, and Determing Control (HIRADC) Di PT Aneka Adhilogam Karya.Surakarta: Universitas Muhammadiyah Surakarta.

Elvianthi Elsa, 2011. Penerapan Keselamatan Dan Kesehatan Kerja (K3) Di PT. Pembangunan Perumahan (PP) (Persero) Pada Proyek Pembangunan Fakultas Kedokteran UISU. Medan: Unimed

Santoso G. Manajemen Keselamatan dan Kesehatan Kerja. Jakarta: Prestasi Pustaka;2004.

Sedarmayanti. 2009. Tata Kerja dan Produktifitas Kerja; Suatu tinjauan dari Aspek Ergonomi Atau Kaitan Antara Manusia Dengan Lingkungan Kerjanya.Bandung: Mandar Maju.

Sugiyono. (2014). Metode Penelitian Pendidikan Pendekatan Kuantitatif, Kualitatif, dan R\&D. Bandung: Alfabeta

Tarwaka.2012.Dasar-dasar Keselamatan Kerja Serta Pencegahan Kecelakaan Di Tempat Kerja. Surakarta: Harapan Press

Tarwaka.(2016).Dasar-dasar Keselamatan Kerja Serta Pencegahan Kecelakaan Di Tempat Kerja. Surakarta: Harapan Press 